\title{
Utility of Screening Fasting Plasma Glucose and Glycated Hemoglobin to Circumvent the Need for Oral Glucose Tolerance Test in Women with Prior Gestational Diabetes
}

\author{
Alpesh Goyal · Yashdeep Gupta (D) · Suraj Kubihal · Mani Kalaivani • \\ Neerja Bhatla $\cdot$ Nikhil Tandon
}

Received: October 31, 2020 / Accepted: December 31, 2020 / Published online: January 20, 2021

(C) The Author(s), under exclusive licence to Springer Healthcare Ltd. part of Springer Nature 2021

\begin{abstract}
Introduction: Our aim is to propose an evidence-based strategy for screening postpartum dysglycemia.

Methods: This study included adult non-pregnant women who were diagnosed with gestational diabetes (GDM) using International Association of Diabetes in Pregnancy Study Group (IADPSG) criteria during their index pregnancy (2012-2019). Eligible participants underwent a concurrent oral glucose tolerance test (OGTT) and glycated hemoglobin (HbA1c) test. A detailed questionnaire documenting relevant personal and medical history was filled, and the relevant anthropometric parameters were recorded.

Results: We evaluated data from 377 women at a mean $( \pm$ SD) age of $32.1 \pm 4.6$ years and at a median duration of 15 (10-33) months following childbirth. Diabetes was diagnosed in 42 $(11.1 \%)$ women. Use of a combination cutoff
\end{abstract}

[fasting plasma glucose $(\mathrm{FPG}) \geq 6.1 \mathrm{mmol} / \mathrm{L}$ or glycated hemoglobin $\quad(\mathrm{HbA} 1 \mathrm{c}) \geq 6.0 \%$ ( $42 \mathrm{mmol} / \mathrm{mol})$ ] avoided OGTT in $80.9 \%$ of the study cohort, without missing the diagnosis of diabetes in any study subject. The diagnosis was missed in $2.4 \%$ of women with diabetes (and $0.3 \%$ of whole cohort) using only the FPG criterion $(\geq 5.6 \mathrm{mmol} / \mathrm{L})$ or $\mathrm{HbA} 1 \mathrm{c}$ criterion $[\mathrm{HbA} 1 \mathrm{c} \geq 5.7 \%(39 \mathrm{mmol} / \mathrm{mol})]$ alone. These tests avoided the need for an OGTT in $75.3 \%$ and $65.5 \%$ of women, respectively.

Conclusions: The proposed strategies are likely to be both patient- and physician-friendly and have the potential to address several barriers for postpartum screening among women with prior GDM.

Keywords: Fasting plasma glucose; Gestational diabetes mellitus; HbA1c; India; OGTT; Postpartum; Screening; South Asia; Strategy

A. Goyal · Y. Gupta ( $₫)$ · S. Kubihal · N. Tandon Department of Endocrinology and Metabolism, All India Institute of Medical Sciences, New Delhi, India e-mail: yashdeep@aiims.edu

M. Kalaivani

Department of Biostatistics, All India Institute of Medical Sciences, New Delhi, India

N. Bhatla

Department of Obstetrics and Gynecology, All India

Institute of Medical Sciences, New Delhi, India 


\section{Key Summary Points}

This study proposes an evidence-based strategy for screening postpartum dysglycemia.

The data in this study are derived from a large cohort of South Asian women who were followed on a long-term basis after the diagnosis of gestational diabetes mellitus using International Association of Diabetes and Pregnancy Study Groups criteria in the index pregnancy.

We propose three screening strategies as an alternative to oral glucose tolerance test (OGTT) during the postpartum period: FPG alone (the most economical approach), HbA1c alone (the most convenient approach), and combined FPG and HbA1c (the overall best approach).

Use of a combination cutoff [FPG $\geq 6.1$ $\mathrm{mmol} / \mathrm{L}$ or $\mathrm{HbA} 1 \mathrm{c} \geq 6.0 \%$ (42 $\mathrm{mmol} / \mathrm{mol}$ )] avoided OGTT in $80.9 \%$ of the study cohort, without missing the diagnosis of diabetes in any study subject.

\section{DIGITAL FEATURES}

This article is published with digital features, including a summary slide, to facilitate understanding of the article. To view digital features for this article go to https://doi.org/10.6084/ m9.figshare.13502574.

\section{INTRODUCTION}

The ongoing coronavirus disease 2019 (COVID19) pandemic caused by severe acute respiratory syndrome coronavirus 2 (SARS-CoV-2) infection has presented an unprecedented challenge to healthcare systems worldwide [1]. On the one hand, hospitals have been strengthened to deal with the increasing number of patients with COVID-19; on the other hand, innovative measures for uninterrupted care of patients with non-COVID illnesses have come to the forefront $[2,3]$. With regard to the antepartum and postpartum care of women with gestational diabetes mellitus (GDM), one needs to strive for the balance between increased risk of viral transmission during repeated hospital visits and potential for adverse pregnancy outcomes and future metabolic complications due to interruption of healthcare delivery [4].

An oral glucose tolerance test (OGTT) remains the gold standard for the diagnosis of GDM and to screen for postpartum dysglycemia among women with a history of GDM [5]. However, OGTTs involve long waiting times, potentially increasing the risk for viral transmission, and place an increased burden on the already overburdened healthcare systems [4]. Tests such as fasting plasma glucose (FPG) and glycated hemoglobin (HbA1c) provide distinct advantages over OGTT in terms of convenience, single time point sampling (avoiding long waiting times), low biological variability (HbA1c), and flexibility for measurement at any time of the day (HbA1c) [6]. For the same reason, several professional organizations have issued revised guidance for screening GDM during the current pandemic. These guidelines highlighted the use of FPG, random plasma glucose (RPG), HbA1c, or screening for GDM on the basis of risk factors, either alone or in combination [7-14]. While a great deal of attention has been focused on antepartum screening, the subject of postpartum glycemic status evaluation has not been adequately addressed.

With this background, we planned this study to propose an evidence-based strategy for screening postpartum dysglycemia. The study involved a secondary analysis of the previously available dataset. This analysis aims to find the answer to a simple but clinically relevant question: could the use of OGTT be avoided in a significant proportion of women with previous GDM if FPG and/or HbA1c is/are used as firststep screening tests? 


\section{METHODS}

\section{Settings and Study Design}

The primary studies on which this secondary data analysis is based were cross-sectional and were carried out at All India Institute of Medical Sciences (AIIMS), New Delhi, India, a tertiary care center dealing with a low- and middle-income population [15]. The institutional ethics committee of AIIMS, New Delhi, India approved these studies (Ref. No. IECPG-177//27.01.2016, RT-4/24.02.2016, dated February 26, 2016 and IECPG-166/19.04.2018, dated April 23, 2018), and we obtained informed written consent from all participants. This study was performed in accordance with the Helsinki Declaration of 1964 and its later amendments.

\section{Inclusion and Exclusion Criteria}

This study included adult non-pregnant women who were diagnosed with GDM using International Association of Diabetes in Pregnancy Study Group (IADPSG) criteria (plasma glucose $\geq 5.1,10.0$, or $8.5 \mathrm{mmol} / \mathrm{l}$ at 0,1 , and $2 \mathrm{~h}$, respectively, on a 75 -g OGTT) during their index pregnancy (2012-2019) [16]. They were registered in the Department of Endocrinology and Metabolism and/or Department of Obstetrics and Gynecology at AIIMS, New Delhi, India. The additional inclusion criteria were postpartum duration of at least 6 weeks and willingness to provide written informed consent. We excluded women with diabetes other than GDM, and those with current pregnancy. We also excluded women with known diabetes on glucose-lowering medications, or those using steroids.

\section{Procedure on Day of Testing}

We invited women in a fasting state and performed an OGTT using $83.3 \mathrm{~g}$ glucose monohydrate (equivalent to $75 \mathrm{~g}$ of anhydrous glucose) dissolved in $250-300 \mathrm{ml}$ water and consumed over 5-10 min. We took samples for plasma glucose estimation at 0 and $120 \mathrm{~min}$ and collected blood in the fasting state for HbA1c measurement. A detailed questionnaire was completed for all participants, documenting relevant personal and medical history. Detail regarding the anthropometric and biochemical variables and their measurements were provided in our previous publications $[15,17]$.

\section{Definitions Used in Study}

Individuals were classified as having normoglycemia [FPG $<5.6 \mathrm{mmol} / \mathrm{L}, 2$-h plasma glucose $<7.8 \mathrm{mmol} / \mathrm{L}$ and $\mathrm{HbA} 1 \mathrm{c}<5.7 \%$ $(39 \mathrm{mmol} / \mathrm{mol})]$, prediabetes by American Diabetes Association (ADA) criteria [FPG 5.6$6.9 \mathrm{mmol} / \mathrm{L}$ and/or 2-h plasma glucose 7.8 $11.0 \mathrm{mmol} / \mathrm{L}$ and/or HbA1c $5.7-6.4 \%$ $47 \mathrm{mmol} / \mathrm{mol})]$, prediabetes by World Health Organization (WHO) criteria [FPG 6.1$6.9 \mathrm{mmol} / \mathrm{L}$ and/or 2-h plasma glucose 7.8 $11.0 \mathrm{mmol} / \mathrm{L}]$, diabetes mellitus $[\mathrm{FPG} \geq$ $7.0 \mathrm{mmol} / \mathrm{L}$ and/or 2-h plasma glucose $\geq 11.1 \mathrm{mmol} / \mathrm{L}$ and/or $\mathrm{HbA} 1 \mathrm{c} \geq 6.5 \%$ $(48 \mathrm{mmol} / \mathrm{mol})][5,18]$. Overweight/obesity and metabolic syndrome were defined as per WHO and International Diabetes Federation (IDF) criteria, respectively $[19,20]$. Hypertension was defined as systolic blood pressure $(\mathrm{SBP}) \geq 140$ $\mathrm{mmHg}$ and/or diastolic blood pressure (DBP) $\geq 90 \mathrm{mmHg}$, or use of drugs for lowering of blood pressure.

\section{Laboratory Methods}

Blood sample for plasma glucose estimation was collected in a gray-top fluoride tube, centrifuged immediately, and transported to the laboratory under cold conditions. Plasma glucose was measured using the hexokinase method on an autoanalyzer. For HbA1c estimation, blood was collected in a purple-top ethylenediaminetetraacetic acid (EDTA) tube. HbA1c was measured using a high-performance liquid chromatography-based ion exchange chromatography method. The inter-assay coefficients of variation $(\mathrm{CV})$ for $\mathrm{HbA1c}$ derived from low- and high-quality control samples were $2.0 \%$ (at a mean HbA1c of $4.9 \%$ or $30 \mathrm{mmol} / \mathrm{mol}$ ) and $2.9 \%$ (at a mean HbA1c of $10.1 \%$ or $87 \mathrm{mmol} / \mathrm{mol}$ ), respectively. Besides, 
the departmental laboratory also participates in an external quality assurance program for these two analytes (glucose and HbA1c) with an acceptable performance.

\section{Sample Size Calculation}

Considering the ADA definition as the gold standard for the diagnosis of diabetes, we calculated sample size for the predictive performance of FPG and $\mathrm{HbA1c}$ in the postpartum period. Considering 95\% confidence interval, $10 \%$ precision, and a sensitivity of $90 \%$, the number of events (subjects with diabetes) was estimated to be 35 . Therefore, for a $10 \%$ prevalence of diabetes, the sample size was estimated to be 350 .

\section{Statistical Analysis}

STATA 15.0 (Stata Corp, College Station, TX, USA) was used for the statistical analyses. Data are presented as $n(\%)$, mean $\pm \mathrm{SD}$ or median (interquartile range). We analyzed the data to calculate sensitivity, specificity, positive predictive value, and negative predictive value of FPG and HbA1c, either alone or in combination, at varying cutoffs for the diagnosis of diabetes. The cutoffs chosen for FPG were $\geq 5.6 \mathrm{mmol} / \mathrm{L}$ and $\geq 6.1 \mathrm{mmol} / \mathrm{L}$, as these are thresholds used by ADA and $\mathrm{WHO}$, respectively, to define impaired fasting glucose $[5,18]$. For $\mathrm{HbA1c}$, the cutoffs chosen were $\geq 5.7 \% \quad(39 \mathrm{mmol} / \mathrm{mol}$, used by ADA to define prediabetes) and $\geq 6.0 \%$ ( $42 \mathrm{mmol} / \mathrm{mol}$, the threshold shown to be predictive of future diabetes) [21].

\section{RESULTS}

\section{Baseline Characteristics}

We evaluated data from 377 women at a mean $( \pm \mathrm{SD})$ age of $32.1 \pm 4.6$ years and a median duration of 15 (10-33) months following childbirth. A family history of diabetes was present in $170(52.3 \%, n=325)$ women. A total of $86(22.8 \%)$ women required insulin during the index pregnancy, while $30(8.0 \%)$ women
Table 1 Baseline characteristics of the study population

\begin{tabular}{ll}
\hline Variable & $\begin{array}{l}\text { Women } \\
(\boldsymbol{n}=377)\end{array}$ \\
\hline Age at current testing (years) & $32.1 \pm 4.6$ \\
Time since index delivery (months) & $15(10-33)$ \\
Family history of diabetes ${ }^{\mathrm{a}}$ & $170(52.3)$ \\
Insulin or oral glucose-lowering drug use & $110(29.2)$ \\
$\quad$ during pregnancy & $29(7.7)$ \\
Past H/O of GDM & $241(63.9)$ \\
Overweight/obese & $22(5.8)$ \\
Hypertension & $136(36.1)$ \\
Metabolic syndrome & \\
\hline Data are mean \pm SD, median (q25-q75) & or $n(\%)$ \\
$G D M$ gestational diabetes mellitus & \\
$n=325$ &
\end{tabular}

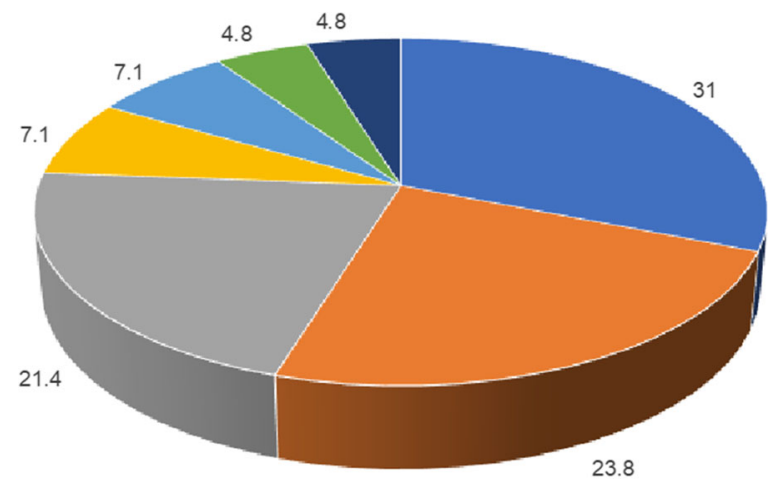

\footnotetext{
- FPG plus 2-h PG plus HbA1c criteria = 2-h PG criteria alone - HbA1c criteria alone $\quad$ FPG + 2h PG criteria both - 2-h PG plus HbA1c criteria both =FPG criteria alone - $F P G+H b A 1 c$ criteria both
}

Fig. 1 Percentage of women diagnosed with diabetes based on elevation of fasting plasma glucose (FPG), glycated hemoglobin (HbAlc), and 2-h plasma glucose (2$h \mathrm{PG}$ ) either alone or in combination

were treated with metformin with or without insulin. Overweight/obesity, metabolic syndrome, and hypertension were present in 241 (63.9\%), $136(36.1 \%)$, and $22(5.8 \%)$ women, 
respectively (Table 1). Diabetes was diagnosed in $42(11.1 \%)$ women, while $167(44.3 \%)$ and 81 (21.5\%) women had prediabetes by ADA and WHO criteria, respectively. Among subjects with diabetes, elevated FPG, 2-h plasma glucose
OGTT, and HbA1c values were present in $47.6 \%, 69.0 \%$, and $64.3 \%$, respectively. Figure 1 presents the proportion of subjects diagnosed with diabetes based on elevation of one or more of these tests.

Table 2 Performance of different screening strategies for diagnosis of diabetes in the study cohort

\begin{tabular}{|c|c|c|c|c|c|c|c|}
\hline Test & $\begin{array}{l}\text { Sensitivity } \\
(\%)(95 \% \\
\text { CI })\end{array}$ & $\begin{array}{l}\text { Specificity } \\
(\%)(95 \% \\
\text { CI) }\end{array}$ & $\begin{array}{l}\text { PPV (\%) } \\
(95 \% \mathrm{CI})\end{array}$ & $\begin{array}{l}\text { NPV (\%) } \\
(95 \% \mathrm{CI})\end{array}$ & $\begin{array}{l}\text { Diagnosis } \\
\text { missed in } \\
\text { total } \\
\text { cohort }\end{array}$ & $\begin{array}{l}\text { Diagnosis } \\
\text { missed in } \\
\text { women } \\
\text { with } \\
\text { diabetes }\end{array}$ & $\begin{array}{l}\text { OGTT } \\
\text { required } \\
\text { to } \\
\text { diagnose } \\
\text { diabetes } \\
(\%)\end{array}$ \\
\hline $\mathrm{FPG} \geq 5.6 \mathrm{mmol} / \mathrm{L}$ & $\begin{array}{c}97.6(87.4 \\
99.9)\end{array}$ & $\begin{array}{c}78.5(73.7 \\
82.8)\end{array}$ & $\begin{array}{c}36.3(31.6, \\
41.3)\end{array}$ & $\begin{array}{c}99.6(97.4 \\
99.95)\end{array}$ & $0.3 \%$ & $2.4 \%$ & $24.7^{a}$ \\
\hline $\mathrm{FPG} \geq 6.1 \mathrm{mmol} / \mathrm{L}$ & $\begin{array}{l}85.7(71.5 \\
94.6)\end{array}$ & $\begin{array}{c}92.5(89.2 \\
95.1)\end{array}$ & $\begin{array}{c}59.0(49.2 \\
68.2)\end{array}$ & $\begin{array}{c}98.1(96.1 \\
99.1)\end{array}$ & $1.6 \%$ & $14.3 \%$ & $10.9^{\mathrm{a}}$ \\
\hline $\begin{array}{l}\mathrm{HbA} 1 \mathrm{c} \geq 5.7 \% \\
\quad(39 \mathrm{mmol} / \mathrm{mol})\end{array}$ & $\begin{array}{c}97.6(87.4 \\
99.9)\end{array}$ & $\begin{array}{c}65.4(60.0 \\
70.5)\end{array}$ & $\begin{array}{c}26.1(23.2, \\
29.2)\end{array}$ & $\begin{array}{c}99.6(96.9 \\
99.9)\end{array}$ & $0.3 \%$ & $2.4 \%$ & 34.5 \\
\hline $\begin{array}{l}\mathrm{HbA} 1 \mathrm{c} \geq 6.0 \% \\
\quad(42 \mathrm{mmol} / \mathrm{mol})\end{array}$ & $\begin{array}{c}88.1(74.4 \\
96.0)\end{array}$ & $\begin{array}{c}85.4(81.2 \\
89.0)\end{array}$ & $\begin{array}{c}43.0(36.3, \\
50.0)\end{array}$ & $\begin{array}{c}98.3(96.2 \\
99.2)\end{array}$ & $1.3 \%$ & $11.9 \%$ & 15.6 \\
\hline $\begin{array}{c}\mathrm{FPG} \geq 5.6 \mathrm{mmol} / \mathrm{L} \\
\quad \text { or } \mathrm{HbAlc} \geq 5.7 \% \\
(39 \mathrm{mmol} / \mathrm{mol})\end{array}$ & $\begin{array}{c}100.0(91.6 \\
100.0)\end{array}$ & $\begin{array}{c}55.2(49.7 \\
60.6)\end{array}$ & $\begin{array}{c}21.9(19.9, \\
24.0)\end{array}$ & 100.0 & 0 & 0 & 42.4 \\
\hline $\begin{array}{l}\mathrm{FPG} \geq 5.6 \mathrm{mmol} / \mathrm{L} \\
\quad \text { or } \mathrm{HbAlc} \geq 6.0 \% \\
(42 \mathrm{mmol} / \mathrm{mol})\end{array}$ & $\begin{array}{c}100.0(91.6 \\
100.0)\end{array}$ & $\begin{array}{c}69.3(64.0 \\
74.2)\end{array}$ & $\begin{array}{c}29.0(25.8, \\
32.4)\end{array}$ & 100.0 & 0 & 0 & 30.0 \\
\hline $\begin{array}{c}\mathrm{FPG} \geq 6.1 \mathrm{mmol} / \mathrm{L} \\
\quad \text { or } \mathrm{HbAlc} \geq 5.7 \% \\
(39 \mathrm{mmol} / \mathrm{mol})\end{array}$ & $\begin{array}{c}100.0(91.6 \\
100.0)\end{array}$ & $\begin{array}{l}63.6(58.2 \\
68.7)\end{array}$ & $\begin{array}{l}25.6(23.0, \\
28.4)\end{array}$ & 100.0 & 0 & 0 & 35.0 \\
\hline $\begin{array}{l}\mathrm{FPG} \geq 6.1 \mathrm{mmol} / \mathrm{L} \\
\quad \text { or } \mathrm{HbAlc} \geq 6.0 \% \\
(42 \mathrm{mmol} / \mathrm{mol})\end{array}$ & $\begin{array}{c}100.0(91.6 \\
100.0)\end{array}$ & $\begin{array}{c}81.5(76.9 \\
85.5)\end{array}$ & $\begin{array}{c}40.4(35.1, \\
45.9)\end{array}$ & 100.0 & 0 & 0 & 19.1 \\
\hline
\end{tabular}

FPG fasting plasma glucose, $H b A 1 c$ hemoglobin A1c, $N P V$ negative predictive value, $O G T T$ oral glucose tolerance test, $P P V$ positive predictive value

a OGTTs along with HbAlc 


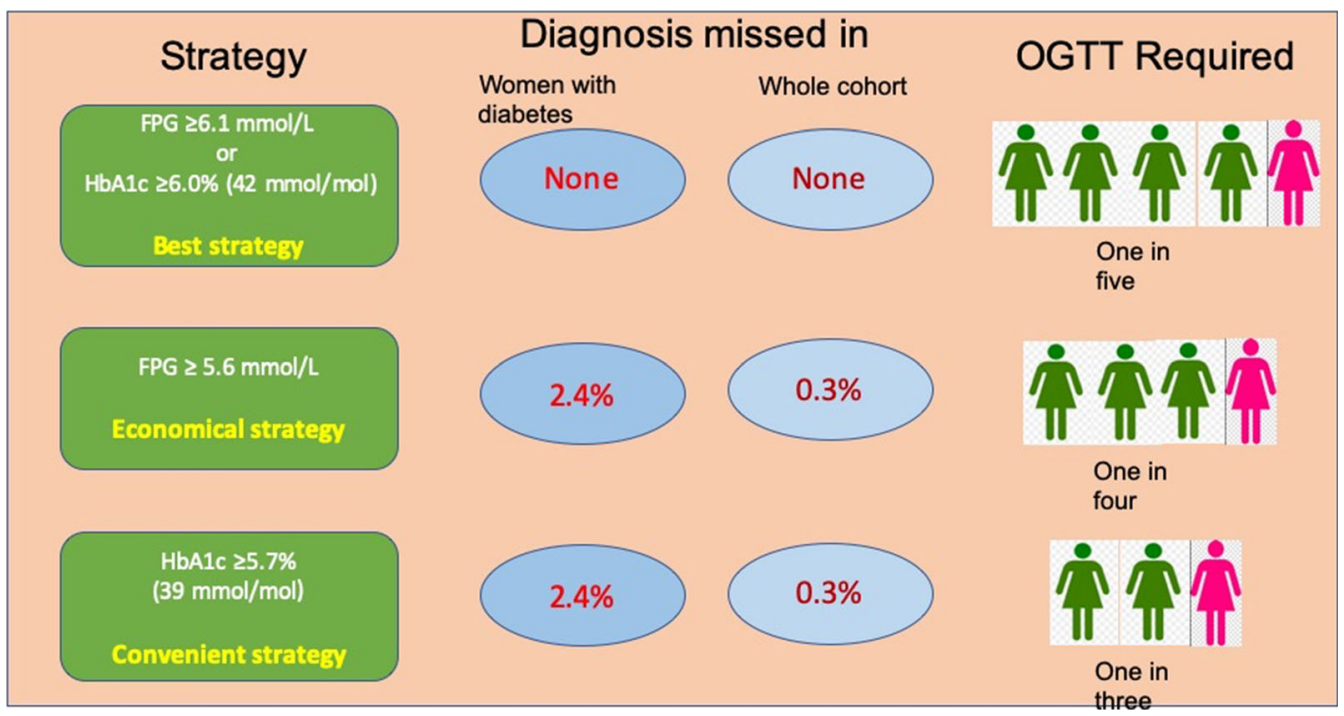

Fig. 2 Proposed strategies for screening of diabetes among women with prior gestational diabetes

\section{Utility of FPG Alone for Diagnosis of Diabetes}

Among 42 subjects with diabetes, 41 (97.6\%) and $36(85.7 \%)$ had FPG $\geq 5.6$ and $\geq 6.1 \mathrm{mmol} /$ $\mathrm{L}$, respectively, and a total of $20(47.6 \%)$ had FPG $\geq 7.0 \mathrm{mmol} / \mathrm{L}$. Among 335 subjects without diabetes, FPG was $<5.6 \mathrm{mmol} / \mathrm{L}$ in 263 $(78.5 \%)$ and $<6.1 \mathrm{mmol} / \mathrm{L}$ in $310(92.5 \%)$. The screening FPG cutoffs of $\geq 5.6 \mathrm{mmol} / \mathrm{L}$ and $\geq 6.1 \mathrm{mmol} / \mathrm{L}$ provided sensitivities of 97.6\% (95\% CI 87.4-99.9\%) and 85.7\% (95\% CI $71.5-94.6 \%)$, respectively, and specificities of 78.5\% (95\% CI 73.7-82.8\%) and 92.5\% (95\% CI 89.2-95.1\%), respectively, for the diagnosis of diabetes (Table 2). Overall, the use of a screening FPG cutoff $\geq 5.6 \mathrm{mmol} / \mathrm{L}$ avoided the need for OGTT and HbA1c in 284 (75.3\%) subjects [264 subjects with FPG $<5.6 \mathrm{mmol} / \mathrm{L}$ and 20 subjects with FPG indicative of diabetes], while missing diabetes in one out of 42 subjects $(2.4 \%)$. With the use of a screening FPG cutoff $\geq 6.1 \mathrm{mmol} / \mathrm{L}$, OGTT and HbA1c were avoided in 336 (89.1\%) subjects, while missing diabetes in six subjects (14.3\%) (Fig. 2, Table 2).

\section{Utility of HbA1c Alone for Diagnosis of Diabetes}

Among 42 subjects with diabetes, 41 (97.6\%) had $\mathrm{HbA} 1 \mathrm{c} \geq 5.7 \% \quad(39 \mathrm{mmol} / \mathrm{mol})$, and 37 $(88.1 \%)$ had $\mathrm{HbA} 1 \mathrm{c} \geq 6.0 \% \quad(42 \mathrm{mmol} / \mathrm{mol})$. Among 335 subjects without diabetes, HbA1c was $<5.7 \% \quad(39 \mathrm{mmol} / \mathrm{mol})$ in $219(65.4 \%)$ and $<6.0 \%(42 \mathrm{mmol} / \mathrm{mol})$ in $286(85.4 \%)$. The screening HbA1c cutoffs $\geq 5.7 \%$ $(39 \mathrm{mmol} / \mathrm{mol}) \quad$ and $\geq 6.0 \% \quad(42 \mathrm{mmol} / \mathrm{mol})$ provided sensitivities of $97.6 \% \quad(95 \% \quad \mathrm{CI}$ 87.4-99.9\%) and $88.1 \%$ (95\% CI 74.4-96.0\%), respectively, and specificities of $65.4 \%$ (95\% CI 60.0-70.5\%) and 85.4\% (95\% CI 81.2-89.0\%), respectively, for the diagnosis of diabetes (Table 2). Overall, the use of screening HbA1c cutoff of $<5.7 \%(39 \mathrm{mmol} / \mathrm{mol})$ avoided the additional need for OGTT for diagnosis of diabetes in $247(65.5 \%)$ subjects [220 with $\mathrm{HbA} 1 \mathrm{c}<5.7 \%(39 \mathrm{mmol} / \mathrm{mol})$ and 27 subjects with HbA1c diagnostic of diabetes], while missing diabetes in one out of 42 subjects $(2.4 \%)$. With use of a screening HbA1c cutoff $\geq 6.0 \%(42 \mathrm{mmol} / \mathrm{mol})$, OGTT was avoided in $318(84.4 \%)$ subjects, while missing diabetes in five subjects (11.9\%) (Fig. 2, Table 2). 


\section{Utility of FPG and HbA1c Combined for Diagnosis of Diabetes}

\section{Cutoff FPG $\geq 5.6 \mathrm{mmol} / \mathrm{L}$ or $\mathrm{HbA1c} \geq 5.7 \%$ (39 mmol/mol)}

All 42 subjects with diabetes had either $\mathrm{FPG} \geq 5.6 \mathrm{mmol} / \mathrm{L} \quad$ or $\quad \mathrm{HbA} 1 \mathrm{c} \geq 5.7 \%$ (39 mmol/mol). On the other hand, among 335 subjects without a diagnosis of diabetes, 185 (55.2\%) had both FPG and HbA1c below these thresholds. Thus, a screening cutoff FPG $\geq 5.6 \mathrm{mmol} / \mathrm{L} \quad$ or $\quad \mathrm{HbA} 1 \mathrm{c} \geq 5.7 \%$ (39 $\mathrm{mmol} / \mathrm{mol})$ provided a high sensitivity (100\%; 95\% CI 91.6-100.0\%) for the diagnosis of diabetes. However, the specificity was low at $55.2 \%$ (95\% CI 49.7-60.6\%) (Table 2). Overall, the use of a screening $\mathrm{FPG} \geq 5.6 \mathrm{mmol} / \mathrm{L}$ or $\mathrm{HbA} 1 \mathrm{c} \geq 5.7 \% \quad(39 \mathrm{mmol} / \mathrm{mol})$ avoided the need for OGTT in 217 (57.6\%) subjects, without missing diabetes in any subject (Fig. 2, Table 2).

\section{Cutoff FPG $\geq 6.1 \mathrm{mmol} / \mathrm{L}$ or $\mathrm{HbA1c} \geq 6.0 \%$ ( $42 \mathrm{mmol} / \mathrm{mol}$ )}

All 42 subjects with diabetes had either $\mathrm{FPG} \geq 6.1 \mathrm{mmol} / \mathrm{L} \quad$ or $\quad \mathrm{HbA} 1 \mathrm{c} \geq 6.0 \%$ $(42 \mathrm{mmol} / \mathrm{mol})$. This cutoff provided a sensitivity of $100 \% \quad(95 \%$ CI $91.6-100.0 \%)$ and specificity of $81.5 \%$ (95\% CI 76.9-85.5\%)] for the diagnosis of diabetes (Table 2). The use of this cutoff avoided the need for an OGTT in 305 $(80.9 \%)$ subjects, without missing diabetes in any subject (Fig. 2, Table 2).

\section{DISCUSSION}

The present study evaluated the utility of FPG and HbA1c either alone or in combination for the diagnosis of diabetes in the postpartum period among women with a history of GDM. On the basis of this study, we propose three screening strategies during the postpartum period: FPG alone (the most economical approach), HbA1c alone (the most convenient approach), and combined FPG and HbA1c (overall best approach). With the use of only the FPG criterion $(\geq 5.6 \mathrm{mmol} / \mathrm{L})$, OGTT and HbA1c could be avoided in $75.3 \%$ of the study cohort while missing the diagnosis in $2.4 \%$ of women with diabetes (and $0.3 \%$ of the entire cohort). The use of only the HbA1c criterion $[\mathrm{HbA} 1 \mathrm{c} \geq 5.7 \%(39 \mathrm{mmol} / \mathrm{mol})]$ avoided OGTT in $65.5 \%$ of the study cohort while missing the diagnosis in $2.4 \%$ of women with diabetes (and $0.3 \%$ of the entire cohort). Finally, use of a combination cutoff $\quad[\mathrm{FPG} \geq 6.1 \mathrm{mmol} / \mathrm{L}$ or HbA1c $\geq 6.0 \%(42 \mathrm{mmol} / \mathrm{mol})]$ avoided OGTT in $80.9 \%$ of the study cohort, without missing the diagnosis of diabetes in any study subject (Fig. 2). The results of this study assume importance given the need to implement evidence-based strategies other than OGTT for the screening of postpartum dysglycemia amidst the social distancing norms during the ongoing COVID-19 pandemic.

As expected, we noted that the sensitivity was higher compared to specificity at a lower FPG $(\geq 5.6 \mathrm{mmol} / \mathrm{L} ; 97.6 \%$ and $78.5 \%$, respectively) and $\mathrm{HbA1c}$ ( $\geq 5.7 \% ; 97.6 \%$ and $65.4 \%$, respectively) cutoffs. On the other hand, the sensitivity decreased with the advantage of increased specificity at higher FPG ( $\geq 6.1 \mathrm{mmol} / \mathrm{L} ; 85.7 \%$ and $92.5 \%$, respectively) and HbA1c ( $\geq 6.0 \% ; 88.1 \%$ and $85.4 \%$, respectively) cutoffs. Therefore, when these tests are used in isolation, the use of a lower but more sensitive cutoff would be preferred in order to avoid a missed diagnosis of diabetes. However, once these tests are used in combination, the sensitivity was found to remain $100 \%$ at various cutoffs, and the use of a higher but more specific cutoff (FPG $\geq 6.1 \mathrm{mmol} / \mathrm{L}$ or $\mathrm{HbA} 1 \mathrm{c}$ $\geq 6.0 \%$ ) would be preferable in order to avoid OGTT in a larger proportion of subjects. On the basis of the performance of these tests, we can conclude that diabetes can be safely excluded in subjects with values below the stated thresholds. On the other hand, for subjects with values greater than these thresholds but less than those diagnostic of diabetes, an OGTT may be needed for confirmation of diabetes. However, in a clinical setting, isolated derangement of 2-h OGTT plasma glucose value is unlikely to warrant pharmacotherapy and, therefore, such subjects could be safely advised lifestyle modifications, and OGTT planned on a future followup visit.

Rather than suggesting a new cutoff based on receiver-operating characteristic (ROC) analysis, we used standard cutoffs suggested by ADA and 
WHO and evaluated their performance for the diagnosis of diabetes. Previously, the focus has mainly remained on the derivation of new cutoffs which provide optimal test performance for the diagnosis of diabetes [22]. However, these cutoffs have varied from one study to another and are challenging to implement uniformly in clinical or research settings.

The United Kingdom National Institute for Health and Care Excellence (NICE) guidelines recommend that OGTT should not be performed routinely in all patients with prior GDM; instead, FPG should be offered at 6-13 weeks postpartum and either of FPG or HbA1c beyond 13 weeks postpartum. These guidelines suggest FPG and HbA1c thresholds of $<6.0 \mathrm{mmol} / \mathrm{L}$ and $<5.7 \% \quad(39 \mathrm{mmol} / \mathrm{mol})$, respectively, to exclude a possibility of diabetes [23]. Our study suggests the use of FPG and HbA1c cutoffs $<5.6 \mathrm{mmol} / \mathrm{L}$ and $<5.7 \%$ $(39 \mathrm{mmol} / \mathrm{mol})$, respectively, to exclude diabetes since both these thresholds are associated with a very high sensitivity $(97.6 \%)$ and negative predictive value $(99.6 \%)$. However, owing to its higher specificity, the use of other tests (OGTT and HbA1c or OGTT alone) could be avoided in a greater proportion of subjects using the FPG approach (75.3\%) compared to the HbA1c approach $(65.5 \%)$. HbA1c is a more convenient test as the sample can be collected at any time of the day; however, the ease of availability and lower cost are clear advantages of FPG in a resource-constrained setting. Similarly, the American Diabetes Association suggests that an ongoing evaluation in the postpartum period may be performed with any of the recommended glycemic tests (e.g., HbA1C, FPG, or 75-g OGTT using non-pregnant thresholds) [5]. Our data suggest that when used in isolation, FPG, HbA1c, and OGTT detected diabetes in $47.6 \%, 64.3 \%$, and $78.6 \%$ of subjects with diabetes (Fig. 1). Clearly, OGTT which combines both FPG and 2-h PG criterion remains the gold standard test for the diagnosis of diabetes. However, the next best strategy could be to use a combination of FPG and $\mathrm{HbA} 1 \mathrm{c}$ as an alternative to OGTT. In our cohort, the use of a combination cutoff $[\mathrm{FPG} \geq 6.1 \mathrm{mmol} / \mathrm{L}$ and $\mathrm{HbA} 1 \mathrm{c} \geq 6.0 \%$ ( $42 \mathrm{mmol} / \mathrm{mol})]$ provided a high sensitivity
(100\%) and intermediate specificity (81.5\%) for the diagnosis of diabetes. This approach avoided the need for OGTT in $80.9 \%$ of subjects, while not missing diabetes in any study subject. Finally, the International Federation of Obstetrics and Gynecology (FIGO) states that there is no clear evidence-based approach for the ongoing surveillance of women with prior GDM [24]. From this perspective, this study's data assume significance since these could aid with informed decision-making at the level of both the patient and healthcare provider.

This study's strengths are its large sample size, use of widely followed standard thresholds for evaluating test performance, and inclusion of both OGTT and HbA1c criteria to define diabetes in the study cohort. The data in this study are derived from a large cohort of South Asian women who were followed on a longterm basis after the diagnosis of GDM using IADPSG criteria in the index pregnancy. We acknowledge certain limitations of this study. The study findings require validation in other populations, especially considering that factors affecting HbA1c, i.e., glycation of hemoglobin for a given plasma glucose level and prevalence of anemia and hemoglobinopathies, vary considerably across different ethnicities [25]. Secondly, while the proposed strategies are likely to be both patient- and physician-friendly and have the potential to address several existing barriers for postpartum screening, their utility in terms of improvement of postpartum screening rates (during or beyond the current pandemic) remains to be seen.

\section{CONCLUSION}

We propose three screening strategies as an alternative to OGTT during the postpartum period: FPG alone (the most economical approach), HbA1c alone (the most convenient approach), and combined FPG and HbA1c (the overall best approach). The use of these strategies could avoid the need for OGTT in $65-80 \%$ of women, while missing diabetes in less than $3 \%$ of women. These strategies may be indispensable to improve the dismal postpartum screening rates. 


\section{ACKNOWLEDGMENTS}

The authors are grateful to the study participants for generously donating their time and information. The authors would like to thank Yatender Singh, Ankit Rajput, Balram, Arun Kumar, Vineeta Garg, Samita Ambekar, and Divya Bhatia for assistance in conducting the study.

Funding. No funding or sponsorship was received for this study or publication of this article

Authorship. All named authors meet the International Committee of Medical JournalEditors (ICMJE) criteria for authorship for this article, take responsibility for the integrity of the work as a whole, and have given their approval for this version to be published.

Authorship Contributions. YG conceptualised the research. AG and YG prepared the initial draft, statistical analysis was done by MK. NT provided guidance throughout the study. AG, YG, SK, MK, NB, and NT helped in execution of the study, interpretation of data, critical review of the manuscript, and final approval of the manuscript. YG is the guarantor of this work and, as such, had full access to all the data in the study and takes responsibility for the integrity of the data and the accuracy of the data analysis.

Disclosures. Alpesh Goyal, Yashdeep Gupta, Suraj Kubihal, Mani Kalaivani, Neerja Bhatla, and Nikhil Tandon have nothing to disclose.

Compliance with Ethics Guidelines. The study was approved by institutional ethics committee of All India Institute of Medical Sciences, New Delhi, India, and we obtained informed written consent from all participants. The study was performed in accordance with the Helsinki Declaration of 1964 and its later amendments.

Data Availability. The datasets generated during and/or analyzed during the current study are available from the corresponding author on reasonable request.

Open Access. This article is licensed under a Creative Commons Attribution-NonCommercial 4.0 International License, which permits any non-commercial use, sharing, adaptation, distribution and reproduction in any medium or format, as long as you give appropriate credit to the original author(s) and the source, provide a link to the Creative Commons licence, and indicate if changes were made. The images or other third party material in this article are included in the article's Creative Commons licence, unless indicated otherwise in a credit line to the material. If material is not included in the article's Creative Commons licence and your intended use is not permitted by statutory regulation or exceeds the permitted use, you will need to obtain permission directly from the copyright holder. To view a copy of this licence, visit http:// creativecommons.org/licenses/by-nc/4.0/.

\section{REFERENCES}

1. WHO Coronavirus Disease (COVID-19) Dashboard. 2020. https://www.who.int/emergencies/diseases/ novel-coronavirus-2019?gclid=CjwKCAjwxev3BR BBEiwAiB_PWAiAHJnXqD7UeeaUgIpRsZ9YJCz Kh715FRZtikNZLIWou-vuAm1z1xoC3BgQAvD_ BwE. Accessed 24 Aug 2020.

2. Hollander JE, Carr BG. Virtually perfect? Telemedicine for Covid-19. N Engl J Med. 2020;382: 1679-81.

3. Webster P. Virtual health care in the era of COVID19. Lancet. 2020;395(10231):1180-1.

4. Thangaratinam S, Cooray SD, Sukumar N, et al. Endocrinology in the time of COVID-19: diagnosis and management of gestational diabetes mellitus. Eur J Endocrinol. 2020;183:G49-56.

5. American Diabetes Association. Classification and diagnosis of diabetes: standards of medical care in diabetes-2020. Diabetes Care. 2020;43(Suppl 1):S1431.

6. Bonora E, Tuomilehto J. The pros and cons of diagnosing diabetes with A1C. Diabetes Care. 2011;34(Suppl 2):S184-90. 
7. Torlone E, Sculli MA, Bonomo M, et al. Recommendations and management of hyperglycaemia in pregnancy during COVID-19 pandemic in Italy. Diabetes Res Clin Pract. 2020;22(166):108345.

8. Torlone E, Festa C, Formoso G, et al. Italian recommendations for the diagnosis of gestational diabetes during COVID-19 pandemic: position statement of the Italian Association of Clinical Diabetologists (AMD) and the Italian Diabetes Society (SID), diabetes, and pregnancy study group. Nutr Metab Cardiovasc Dis. 2020;30:1418-22.

9. Royal College of Obstetricians and Gynaecologists. Guidance for maternal medicine services in the evolving coronavirus (COVID-19) pandemic. 2020. https://www.rcog.org.uk/globalassets/documents/ guidelines/2020-07-10-guidance-for-maternalmedicine.pdf. Accessed 29 Aug 2020.

10. Yamamoto JM DL, Reig DS, Berger H. Urgent update - temporary alternative screening strategy for gestational diabetes screening during the COVID-19 pandemic. 2020. https://els-jbs-prod-cdn.jbs. elsevierhealth.com/pb/assets/raw/Health\% 20Advance/journals/jcjd/JCJD_COVID_guidelines_ 020420-1585856697530.pdf. Accessed 29 Aug 2020.

11. Australasian Diabetes in Pregnancy Society (ADIPS). Diagnostic testing for gestational diabetes mellitus (GDM) during the COVID-19 pandemic: antenatal and postnatal testing advice. Sydney: ADIPS [updated 2020 Apr 30; cited 2020 May 2]. 2020. https:// www.adips.org/documents/COVID19-WITHQLDGUI DELINES0704201150ADIPSADSADEADAupdated_ 000.pdf. Accessed 29 Aug 2020.

12 Kasuga Y, Saisho Y, Ikenoue S, Ochiai D, Tanaka M. A new diagnostic strategy for gestational diabetes during the COVID-19 pandemic for the Japanese population. Diabetes Metab Res Rev. 2020. https:// doi.org/10.1002/dmrr.3351.

13. Vambergue A, Jacqueminet S, Lamotte MF, et al. Three alternative ways to screen for hyperglycaemia in pregnancy during the COVID-19 pandemic. Diabetes Metab. 2020;46:507-10.

14. McIntyre HD, Gibbons KS, Ma RCW, et al. Testing for gestational diabetes during the COVID-19 pandemic an evaluation of proposed protocols for the United Kingdom, Canada and Australia. Diabetes Res Clin Pract. 2020;167:108353.

15. Goyal A, Gupta Y, Kalaivani M, et al. Long term (>1 year) postpartum glucose tolerance status among Indian women with history of gestational diabetes mellitus (GDM) diagnosed by IADPSG criteria. Diabetes Res Clin Pract. 2018;142:154-61.
16. International Association of Diabetes and Pregnancy Study Groups Consensus Panel, Metzger BE, Gabbe SG, et al. International Association of Diabetes and Pregnancy Study Groups recommendations on the diagnosis and classification of hyperglycemia in pregnancy. Diabetes Care. 2010;33:676-82.

17. Goyal A, Gupta Y, Kalaivani M, et al. Concordance of glycaemic and cardiometabolic traits between Indian women with history of gestational diabetes mellitus and their spouses: an opportunity to target the household. Diabetologia. 2019;62(8):1357-65.

18. Definitions and diagnosis of diabetes and intermediate hyperglycemia. WHO 2006 Document. 2020. https://www.who.int/diabetes/publications/ diagnosis_diabetes2006/en/. Accessed 24 Aug 2020.

19. WHO definition of overweight and obesity. 2020. https://www.who.int/news-room/fact-sheets/ detail/obesity-and-overweight. Accessed 24 Aug 2020.

20. The IDF consensus worldwide definition of the metabolic syndrome. 2020. https://www.idf.org/elibrary/consensus-statements/60-idfconsensusworldwide-definitionof-the-metabolic-syndrome. html. Accessed 24 Aug 2020.

21. Zhang X, Gregg EW, Williamson DF, et al. A1C level and future risk of diabetes: a systematic review. Diabetes Care. 2010;33:1665-73. https://doi.org/10. 2337/dc09-1939.

22. Su X, Zhang Z, Qu X, Tian Y, Zhang G. Hemoglobin A1c for diagnosis of postpartum abnormal glucose tolerance among women with gestational diabetes mellitus: diagnostic meta-analysis. PLoS One. 2014;9(7):e102144.

23. Diabetes in pregnancy: management from preconception to the postnatal period. 2020. https://www. nice.org.uk/guidance/ng3/resources/diabetes-inpregnancy-management-from-preconception-tothe-postnatal-period-51038446021. Accessed 24 Aug 2020.

24. Sheiner E, Kapur A, Retnakaran R, et al. FIGO (International Federation of Gynecology and Obstetrics) postpregnancy initiative: long-term maternal implications of pregnancy complications-follow-up considerations. Int J Gynaecol Obstet. 2019;147(Suppl 1):1-31.

25. Cavagnolli G, Pimentel AL, Freitas PA, Gross JL, Camargo JL. Effect of ethnicity on HbA1c levels in individuals without diabetes: systematic review and meta-analysis. PLoS One. 2017;12(2):e0171315. 